\title{
Erhöhen Mentholzigaretten das Schlaganfallrisiko zusätzlich?
}

\begin{abstract}
Gehen Raucher, die Mentholzigaretten rauchen, das gleiche Risiko ein wie Raucher, die Zigaretten ohne Mentholgeschmack bevorzugen? Es gibt den Verdacht, dass es besonders schwer ist, mit dem Rauchen aufzuhören, wenn man an Mentholzigaretten gewöhnt ist. Andererseits soll die Lungenkrebsinzidenz bei Mentholrauchern etwas niedriger sein als bei Nicht-Mentholrauchern. Wissenschaftliche Untersuchungen zum Thema gibt es bisher kaum.
\end{abstract}

— Im Rahmen des National Health and Nutrition Examination Surveys (NHANES) haben jetzt Forscher der Universität Toronto die Daten von 5167 Rauchern aus den Jahren 2001 bis 2008 ausgewertet. Bei der Untersuchung wurden auch die soziale Herkunft, das Ge- schlecht und die Rauchgewohnheiten ermittelt. 26\% der Probanden rauchten Mentholzigaretten, $74 \%$ Zigaretten ohne diesen Geschmack.

Wurden die Daten nach Alter, Geschlecht und Gewicht korrigiert, zeigte sich, dass 2,25 mal mehr Mentholraucher einen Schlaganfall durchgemacht hatten als Nicht-Mentholraucher. Bei
Frauen und Nicht-Afroamerikanern steigerte der Konsum von Mentholzigaretten das Schlaganfallrisiko sogar um mehr als den Faktor 3.

Bei Hypertonie, COPD, Herzinfarkt und Herzinsuffizienz zeigten sich zwischen den Mentholrauchern und den Normalrauchern keine statistisch signifikanten Unterschiede.

\section{Kommentar}

Zigarettenrauchen schadet grundsätzlich der Gesundheit. Wer zu Mentholzigaretten greift, geht ein zusätzliches Risiko ein: Das bei Rauchern sowieso erhöhte Schlaganfallrisiko wird mindestens noch einmal verdoppelt. Über das warum kann bisher nur spekuliert werden. Der kühlende Effekt des Menthols erlaubt es, den Qualm länger in der Lunge zu behalten, wo er entsprechend länger seine schädigende Wirkung entfalten kann. Schwer verständlich ist allerdings, wieso dann nicht auch ein erhöhtes Risiko für Hypertonie, Herzerkrankungen und COPD beobachtet wird. Hier bleibt also noch viel zu Forschen.

K. MALBERG =

- N. Vozoris

Mentholated cigarettes and cardiovascular and pulmonary diseases: a population-based study. Arch. Int. Med. 172 (2012) 590-591

\section{Zunehmende Pollenallergie, eine Folge des Klimawandels?}

\section{Die Menschen in Europa sind einer immer größeren Pollenkonzentration ausgesetzt. Schuld daran könnte die $\mathrm{CO}_{2}$-Konzentration in der Luft sein.}

_ Langzeitmessungen wurden in $13 \mathrm{eu}$ ropäischen Ländern von einem internationalen Team ausgewertet. Danach sind Städte besonders betroffen. Im Durchschnitt habe die Pollenbelastung dort um 3\% pro Jahr zugenommen. In ländlichen Gebieten war es nur $1 \%$.

Die wahrscheinlichste Ursache für diese Zunahme ist weniger der Temperaturanstieg als vielmehr die steigende $\mathrm{CO}_{2}$-Konzentration in der Luft. Versuche haben gezeigt, dass eine höhere $\mathrm{CO}_{2}$-Konzentration das Pflanzenwachstum und damit die Pollenproduktion fördert. Mildere Temperaturen und zu-

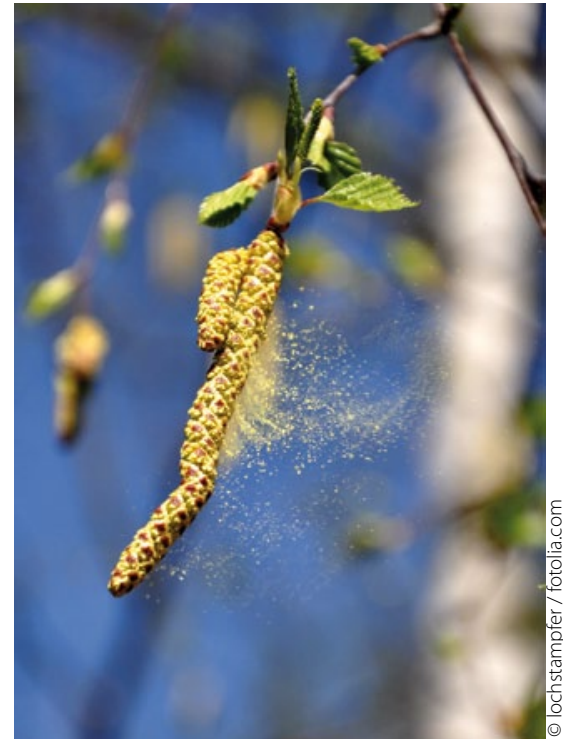

Pollenbelastung: in den Städten höher als auf dem Land. gewanderte Pflanzenarten verlängern die Pollenflugsaison. Das Stadtklima ist bereits wärmer und trockener, hinzu kommt eine höhere Luftverschmutzung, was die Unterschiede zwischen Stadt und Land erklären würde.

\section{Kommentar}

Der Klimawandel ist nicht nur für die Stadtbewohner unerfreulich, so die Autoren. Schon heute leidet fast jeder Dritte in Deutschland unter Allergien, die Tendenz ist steigend.

K. MALBERG = 